\title{
El espacio y el debate sobre la identidad en El viaje sedentario (1994) de Gonzalo Celorio
}

Yazmín Alfaro Cruz

Alfaro Cruz, Y. (2021). El espacio y el debate sobre la identidad en El viaje sedentario (1994) de Gonzalo Celorio. Revista de Filología y Lingüística de la Universidad de Costa Rica, 47(2), e46413. doi: https://doi.org/10.15517/rfl.v47i2.46413

\section{(c) $\mathbb{P Q \Theta O}$}

Doi: https://doi.org/10.15517/rfl.v47i2.46413

URL: https://revistas.ucr.ac.cr/index.php/filyling/index 
Revista de Filología y Lingüística de la Universidad de Costa Rica

ISSN: 0377-628X

ISSN: 2215-2628

filyling@gmail.com

Universidad de Costa Rica

Costa Rica

\title{
El espacio y el debate sobre la identidad en El viaje sedentario (1994) de Gonzalo Celorio
}

\author{
Alfaro Cruz, Yazmín \\ El espacio y el debate sobre la identidad en El viaje sedentario (1994) de Gonzalo Celorio \\ Revista de Filología y Lingüística de la Universidad de Costa Rica, vol. 47, núm. 2, e46413, 2021 \\ Universidad de Costa Rica, Costa Rica \\ Disponible en: http://www.redalyc.org/articulo.oa?id=33266553005 \\ DOI: https://doi.org/10.15517/rfl.v47i2.46413
}

\section{(c) $(1) \Theta \Theta$}

Esta obra está bajo una Licencia Creative Commons Atribución-NoComercial-SinDerivar 3.0 Internacional. 


\section{El espacio y el debate sobre la identidad en El viaje sedentario (1994) de Gonzalo Celorio}

\section{The Space and Debate about the Identity in El Viaje Sedentario (1994) by Gonzalo Celorio}

Yazmin Alfaro Cruz

Ministerio de Educación Pública (MEP), Nandayure,

Guanacaste, Costa Rica

yazminalfaro49@gmail.com

iD https://orcid.org/0000-0003-2512-2015
DOI: https://doi.org/10.15517/rfl.v47i2.46413

Redalyc: http://www.redalyc.org/articulo.oa?id=33266553005

Recepción: 21 Julio 2020

Aprobación: 15 Septiembre 2020

\section{Resumen:}

Este artículo tiene como propósito el estudio del espacio/tiempo en El viaje sedentario (1994) de Gonzalo Celorio, a su vez, pretende vincular estas manifestaciones espacio-temporales como parte del debate en torno a la identidad. Para ello, se tomó como base teórica la geografía literaria: los estudios de Bajtín y Ottmar Ette sobre el cronotopo y la literatura en movimiento. La investigación propone el análisis de los movimientos realizados por el protagonista a lo largo del texto y la forma en que los referentes espacio-temporales se vinculan estrechamente con el proceso de construcción de una identidad. Finalmente, queda demostrado que los espacios descritos en El viaje sedentario (1994) se encuentran relacionados con esa creciente necesidad de identificarse dentro de un colectivo, ejemplo de esto son los vestigios arquitectónicos aún conservados en la ciudad de México y que representan el devenir histórico y la identidad de un pueblo. Así, México en su totalidad se visualiza como el cronotopo del encuentro donde convergen presente y pasado y en él se acumulan capas de sentido e históricas, desde la época colonial hasta la actual.

Palabras ClaVe: cronotopo, literatura en movimiento, espacio, identidad, identidad latinoamericana.

\section{Abstract:}

The purpose of this article is to study space/time in El Viaje Sedentario (1994) by Gonzalo Celorio, at the same time, to link these spatio-temporal manifestations as part of the debate on identity. For this purpose, literary geography was taken as a theoretical basis: Bajtín and Ottmar Etter's studies on the chronotope and literature in movement. The research proposes the analysis of the movements made by the protagonist throughout the text and the way in which the referents spatio-temporal are closely related to the process of constructing an identity. Finally, it is demonstrated that spaces described in El Viaje Sedentario (1994) are related to the increasing need to identify oneself within a group, for example, the architectural vestiges that are still preserved in Mexico City, and that represent the historical evolution and identity of a people. Thus, Mexico as a whole is visualized as the chronotope of the encounter where present and past converge and where layers of meaning and histories accumulate, from colonial times to the present.

KEYWORDS: chronotope, literature on the move, space, identity, Latin American identity.

\section{INTRODUCCIÓN}

Esta investigación se centra en una de las obras narrativas del escritor mexicano Gonzalo Celorio Blasco: El viaje sedentario (1994). A través del texto se visualizan diversos aspectos que giran en torno al discurso identitario, y sobresalen aquellos que de alguna manera representan las raíces de la cultura mexicana, su origen, conformación e infraestructura. Conforme se avanza en la lectura, se observa que esta concepción de una identidad va más allá de un territorio, pues se percibe un ideal que involucra no solo a México, sino a Latinoamérica en general y cómo los procesos históricos de esta han quedado plasmados a través del tiempo. Prueba genuina de dichos procesos, según Celorio, vienen a ser los monumentos, edificios y algunos vestigios 
de la arquitectura colonial y mexica, que a pesar de los años se conservan para recordarnos parte de lo vivido por una cultura durante su descubrimiento y "civilización".

Con este trabajo se pretende ahondar en los referentes espacio/temporales del texto mencionado, en relación con las manifestaciones del discurso de identidad. Sin duda alguna, esta propuesta nos llevará a reflexionar sobre la temática y la forma en que se constituyen los discursos en torno a la identidad de un pueblo, en este caso, tomando como referencia la cultura de México.

\section{ANTECEDENTES}

En el artículo "México, ciudad de papel, de Gonzalo Celorio" (1998), Peter Krieger afirma que:

[...] para Celorio, la historia de la formación urbana, desde México- Tenochtitlan hasta la megalópolis de hoy, es la historia de sus destrucciones permanentes. Cada época inventa su propia ciudad, sus propias arquitecturas, mismas que deberían expresar la voluntad del tiempo en el espacio (p. 165).

Resulta importante destacar que el interés y las menciones sobre arquitectura, edificios y todas aquellas estructuras que conforman el concepto de ciudad, son temáticas o aspectos de gran interés para el autor en estudio. Así que no es casualidad que las remita constantemente en algunas de sus obras, tal y como lo hace en El viaje sedentario (1994).

De acuerdo con lo expuesto por Krieger (1998), Celorio, de cierta forma, logra plasmar en sus obras esa preocupación por reflexionar y establecer comparaciones entre la nueva infraestructura de la Ciudad de México, en contraste con la de épocas anteriores. Como parte de esta investigación se tratará de demostrar cómo dicha preocupación inicial se va vinculando de forma paulatina con el surgimiento de un debate que involucra la existencia o búsqueda de la identidad del ser mexicano.

Krieger (1998), por último, menciona que "Gonzalo Celorio define a la ciudad de México como 'atroz y amada, fascinante y desoladora, inhabitable e inevitable” (p. 165). Se observa, en este sentido, cómo la concepción de la ciudad evoca, según este crítico, percepciones ambivalentes o contradictorias; se trata de una concepción bastante compleja según la perspectiva o visión que evoca el autor. Luego, resulta interesante la referencialidad que se realiza sobre la trascendencia histórica de los elementos arquitectónicos, y es que, según el crítico: "La memoria urbana sólo sobrevive en lo que Celorio llama la ciudad de papel, es decir en las descripciones, himnos y novelas que nos permiten revitalizar las ricas dimensiones históricas” (Krieger, 1998, p. 165).

En relación con este tópico de la memoria/historia, se menciona que:

[...] los monumentos arquitectónicos sobrevivientes sólo dan un resplandor modesto de lo que hizo de esta ciudad una de las más fascinantes del mundo. Con la memoria urbana depositada en la literatura, se intensifica la nostalgia por los valores perdidos en la megalópolis actual (Krieger, 1998, p. 166).

En tal sentido, no se trata solo de un aprecio por la arquitectura de la Ciudad de México, sino del significado que implica para sus habitantes, lo cual involucra aquellos elementos que la hacen única o particular en relación con otros espacios del mundo. A su vez, tal estado de reflexión guía al mexicano a ese sentimiento de añoranza por el pasado gratificante. También, aquí la función que ejerce la literatura se muestra, según el crítico, como ese medio de transmisión que logra plasmar o incluso retroalimentar la memoria colectiva, la nostalgia por los tiempos de auge y esplendor en la nación mexicana.

En el artículo de Rosa Beltrán "Los raros: El metal y la escoria, de Gonzalo Celorio" (2014), publicado en la Revista de la Universidad de México, la autora realiza un análisis crítico sobre la novela El metaly la escoria, de Gonzalo Celorio. La obra retrata parte de la historia de México durante la segunda mitad del siglo XIX, a través de un personaje que migra desde España hasta México. Sobre la novela, Beltrán (2014) señala: 
El metal y la escoria es una novela pero es también una memoria de los modos de vida y las mentalidades de cuando menos tres generaciones; es un fresco donde la mirada se detiene en ciertos momentos y ciertos sitios: el mercado de la Merced; el Zócalo de la Ciudad de México; las modernas urbanizaciones de Cedros, Romero de Terreros y Mixcoac; los bares y calles centrales de Madrid; el camino de Santiago y el pueblo de Vibaño en Asturias, de donde salió el abuelo Emeterio Celorio hacia La Habana y de ahí a México para no regresar a la Madre Patria jamás. Y en segundo y más importante lugar, se vuelve compleja porque en esta búsqueda de sí mismo que es la novela ocurre una disociación que es para mí una de las partes más fascinantes de esta historia (p. 92).

De acuerdo con la cita y el artículo en mención, se remite a otra de las obras de Celorio que una vez más evocan al pasado de México. Claramente, la articulista describe el texto como una memoria, de esta manera, explica que la intención de tal memoria histórica consiste en transportarnos a otros tiempos/espacios que, de forma similar a las raíces del autor (España, Cuba y México), se mezclan y encuentran entrelazados. Se evidencia una inquietud o incertidumbre por querer autodefinirse, bien lo argumenta la autora en el artículo cuando escribe que "en esta novela hay una permanente tensión entre querer saber quién se es y una imposibilidad de saberlo" (Beltrán, 2014, p. 93). Reflexiona, además, sobre "esa idea del pasado como algo irrecuperable pero necesario para explicarnos a nosotros mismos” (Beltrán, 2014, p. 92).

En "Tres lindas cubanas de Gonzalo Celorio" (2006), Rosa Beltrán cuestiona:

¿Quién habla a través de nosotros cuando decimos ser quienes somos?, eso fue lo primero que me pregunté al abrir Tres lindas cubanas [...] ¿Por qué ha elegido narrarse desde su cubanidad? "De los ochenta kilos que peso, cuarenta son cubanos”, dice Gonzalo en repetidas ocasiones. Y sin decirlo, dice algo más enigmático aún: los cuarenta kilos mexicanos que él es sólo pueden explicarse a través de los cuarenta kilos cubanos, y en cuanto a éstos, al menos tres cuartas partes pertenecen a su madre y a sus dos tías (p. 96).

Según el fragmento anterior, queda evidenciada la recurrencia de temáticas a lo largo de la obra de Gonzalo Celorio, se trata de esa búsqueda constante de sus raíces, una búsqueda entrañable que lo transporta con frecuencia al pasado y que, en este caso, se enfoca en dar a conocer ese apego, orgullo y admiración por una parte de su identidad: Cuba. Es así como, a través de las voces femeninas de su familia, Celorio viene a plasmar su cubanidad, cuyo eje principal sin duda sería su madre, quien había sido criada en dicha isla.

Una vez analizadas estas fuentes críticas, queda de manifiesto el interés por el tópico de una búsqueda o reafirmación de la identidad, la cual, con toda seguridad, se desprende en cada una de las propuestas literarias del autor, mencionadas con anterioridad.

\section{Fundamentos teóricos}

\subsection{La geografía en la literatura: cronotopo y literatura en movimiento}

En este apartado se tratarán de referir algunos fundamentos o propuestas de análisis en torno a la geografía literaria (estudios que involucren el análisis del espacio/tiempo y los movimientos hermenéuticos en la literatura) y la forma en que se vinculan con este trabajo investigativo. Así, en relación con las manifestaciones de la geografía en los textos literarios, Bajtín (1986) estudia precisamente la relación ineludible entre el tiempo y el espacio:

\footnotetext{
A la intervinculación esencial de las relaciones temporales y espaciales asimiladas artísticamente en la literatura, la llamaremos cronotopo (lo que traducido literalmente significa tiempoespacio). Este término se utiliza en las ciencias naturales matemáticas y fue introducido y fundamentado sobre el terreno de la teoría de la relatividad (de Einstein) [...] nosotros lo trasladamos aquí, a la teoría literaria, casi como una metáfora (casi no totalmente) [...] Entendemos el cronotopo como una categoría formal y de contenido de la literatura [...] (p. 269).
}

De acuerdo con lo anterior, espacio y tiempo son dos elementos inseparables dentro del texto literario, ambos se complementan al punto de que la existencia de uno implica la manifestación del otro, es decir, se 
funden para conformar la concepción o concepto de cronotopo. Luego, el teórico amplía y, al respecto de esta unificación, explica:

En el cronotopo literario- artístico tiene lugar una fusión de los indicios espaciales y temporales en un todo consciente y concreto. El tiempo aquí se condensa, se concentra y se hace artísticamente visible; el espacio en cambio, se intensifica, se asocia al movimiento del tiempo, del argumento, de la historia [...] por este cruzamiento de las series y por esta fusión de los indicios se caracteriza el cronotopo artístico (Bajtín, 1986, p. 269).

En este sentido, en el cronotopo literario no se da importancia a los espacios por sí solos, ya que de ser así estaríamos ante un panorama estático; es a través de la intervención del tiempo que se le proporciona movimiento y vivacidad al elemento espacial. Ese carácter activo es lo que convierte en trascendental una obra literaria. Respecto al valor representativo de los cronotopos, Bajtín (1986) indica que "el tiempo adquiere en ellos un carácter sensiblemente evidente; los hechos del argumento en el cronotopo se concretan, materializan, se llenan de 'sangre' [...]" (p. 460). Es el tiempo "histórico" aquel que le proporciona vitalidad, sentido y movimiento al relato en general.

Las ideas expuestas encuentran cierta vinculación con los planteamientos realizados por De Certeau en su obra La invención de lo cotidiano (2007), cuando afirma que “[...] el espacio es un cruzamiento de movilidades [...] es en efecto producido por las operaciones que lo orientan, lo circunstancian, lo temporalizan y lo llevan a funcionar como una unidad polivalente" (p. 129).

De acuerdo con el estudio del crítico Ottmar Ette (2008), a través del texto literario y en lo que respecta a la literatura de viajes, podrían manifestarse una diversidad de espacios y movimientos. Esta situación quedaría evidenciada a través del recorrido físico o mental de los personajes, ya que tal y como lo expresa el autor: "el viaje no implica necesariamente un movimiento físico" (p. 55). Con respecto a la temática del viaje y los espacios que este implica, Ette (2008) menciona que:

[...] el relato de viajes es, en esencia, aquella forma de escritura literaria y científica en la cual el escribir quizá tenga más conciencia de su referencialidad al espacio, su dinámica y su necesidad de movimiento [...] incluso en el estudio mismo de los relatos de viaje es sorprendente cuán pocas veces se ha formulado la pregunta acerca de sus lugares o espacios (p. 23).

La preocupación del teórico se centra en el hecho de que las investigaciones sobre la escritura de relatos de viajes resultan de tal importancia, pues proporcionan nuevos datos y perspectivas en torno a la literatura misma y su función dentro de las sociedades. Como, por ejemplo, el hecho de retratar una cultura en sí. Otro aspecto al que remite Ette (2008) en su estudio y que se relaciona con este trabajo investigativo corresponde a uno de los apartados sobre las posibles dimensiones del relato de viajes, donde:

La cuarta dimensión del relato de viajes es, hablando en términos de Lévi Strauss, la del tiempo. El viajero se mueve por un lado en el devenir cronológico de su país de origen [...] Así el espacio y el tiempo no sólo están ligados de forma estrechísima, sino que, a su vez, están acoplados al tiempo del propio espacio. El viajero [...] carga con su propio tiempo (Ette, 2008, p. 29).

Con base en lo anterior, es en la cuarta dimensión que Ette (2008), al igual que otros críticos, destaca una vez más la presencia indispensable del tiempo cuando estamos ante el estudio o análisis del espacio literario, donde el movimiento físico/temporal ocurre con la presencia y dinamismo del viajero (personaje). Los presupuestos teóricos referidos en este apartado sirven de sustento y justifican cada uno de los movimientos espaciales y temporales que el protagonista (Gonzalo) realiza a lo largo de El viaje sedentario (1994), y es que tal y como el título lo sugiere, se trata de un viaje temporal, facilitado por la memoria histórica y los recuerdos del personaje.

\subsection{Espacio e identidad}

Resulta interesante cómo en algunos textos se dan constantes menciones a los espacios, descritos en ocasiones de una forma entrañable. Cuando nos encontramos ante tal situación, es inevitable caer en reflexiones sobre 
si algunos textos poseen una intención cohesionadora o, por decirlo de otra manera, generan un llamado a tomar conciencia sobre aquellos sitios que dieron origen a un ser o una cultura en sí. Podría tratarse, incluso, de que estemos ante una intención leve de reafirmar, mediante la literatura, aquello que podría concebirse como identidad, es decir, aspectos que caracterizan y diferencian a un individuo dentro de un colectivo.

Al respecto, Fernando Aínsa en su estudio Identidad cultural de Iberoamérica en su narrativa (1986) menciona:

Todo hombre es -en principio- el punto nodal de una serie de fuerzas que confluyen radialmente desde diferentes puntos del espacio circundante en su persona. Uniendo todos esos puntos entre sí, con el yo individual como punto céntrico, se tiene la imagen de un círculo que incluye todo lo que es encuentro entre el individuo y el resto del mundo. Esta representación de un círculo no pasa de ser una imagen, porque el hombre tiende siempre a estar en desarrollo y mantiene una permanente actividad de relación y percepción (p. 199).

De acuerdo con Aínsa (1986), el individuo se ve influenciado por diferentes fuerzas, las cuales lo rodean y permanecen en su entorno; lo anterior podría involucrar al contexto sociocultural en el que, de forma inevitable, se encuentran insertos cada uno de los habitantes de un espacio geográfico determinado. Sin embargo, el ser humano no se presenta, según Aínsa (1986), como un ente estático que simplemente se nutre de impulsos o fuerzas externas, se concibe como un ser cambiante que evoluciona en su espacio mismo y que se nutre no solo de esas fuerzas cercanas. Dicha interacción con el mundo lo pueden guiar incluso a otras dimensiones (espaciales, temporales, reflexivas) y, como consecuencia, percibir otras realidades que relaciona con las ya adquiridas e involucrar la de otros.

Más adelante, el teórico también afirma que:

[...] en efecto, toda búsqueda de identidad se manifiesta psicológicamente por un anhelo de locomoción, tanto por lo que este expresa como estado en actividad o "andar en algo", como por lo que supone de traslado en el mismo, inherente al cambio de escenario y a la potencial en alguno de ellos (Aínsa, 1986, p. 201).

Esta forma de pensar respecto a la concepción de "espacio" nos lleva a reflexionar sobre la diversidad de estos, los cuales a su vez se encuentran marcados o delimitados de acuerdo con las ideologías o aspectos culturales que tengan en común un grupo de personas. Una vez establecidos esos aspectos que se comparten, es ahí desde donde se teje el ideal de identidad, una serie de factores que unifican, pero a la vez establecen diferencias entre determinados grupos.

Desde el proceso histórico de la conquista en América han surgido debates con respecto a la autodefinición del ser latinoamericano, reflexiones que giran en torno a la diferenciación del individuo dentro de un colectivo (mundo); esto nos lleva a innumerables cuestionamientos, pues definirse a partir del yo implicaría observar y delimitar a ese otro con el fin de evidenciar hasta qué punto son semejantes o contrastantes; he aquí donde sale a colación el término alteridad. Al respecto, Amaryll Chanady en su texto "Nuestra América mestiza y la conceptualización de la especificidad latinoamericana" (1996) agrega:

La conceptualización del otro es sumamente compleja en América Latina, donde el otro constituye una heterogeneidad interna dentro de una sociedad que se considera con frecuencia como periférica con respecto a los centros metropolitanos, donde el proceso de construcción identitaria es todavía muy actual, y donde el deseo de autoafirmación y la resistencia frente a la dominación externa [...] son muy evidentes (p. 85).

De esta manera, se considera que los debates acerca del proceso de construcción identitaria en América Latina resultan complejos, y esto se debe en gran parte a la gama de diversidad cultural, étnica e ideológica; a la mezcla de diversos pueblos que han venido coexistiendo en un mismo espacio y no solo eso, sino que cada país latinoamericano ha vivido una serie de procesos históricos particulares. A lo largo de su historia, los pueblos latinoamericanos han sido constantes en esa búsqueda de una identidad, lo cual se venía gestando desde los innumerables intentos por liberarse de los dominios de la Corona española. Fue así como los movimientos independentistas recorrieron el territorio latinoamericano de norte a sur e intensificaron ese deseo de libertad aunado al propósito de construir un modelo identitario que viniese a justificar por qué era necesaria una 
independencia, pues los rasgos, costumbres, condiciones, clima e incluso orografía eran distintos con respecto a Europa.

$\mathrm{Al}$ respecto sobre esta mezcla y complejidad, la autora, en el artículo mencionado, comenta:

Fernando Aínsa, por ejemplo, subraya el carácter dinámico de la identidad cultural latinoamericana, que describe como un proceso dialéctico permanente entre tradición y novedad, continuidad y ruptura, integración y cambio, evasión y arraigo, apertura hacia <otras> culturas y repliegue aislacionista y defensivo sobre sí misma, dinámica que se traduce en un doble movimiento: el centrípeto nacionalista y el centrífugo universalista (Chanady, 1996, p. 88).

Lo anterior confirma esa complejidad sobre la identidad cultural latinoamericana, la cual se describe a sí misma a partir de dicotomías en ese intento por unificar u homogeneizar una cultura que de forma inevitable se encuentra permeada por la diversidad. Al llegar a este punto, no se podría dejar de referir la construcción o concepto que en la actualidad se conoce como sincretismo cultural, el cual alude de forma directa a esta discusión que involucra los debates en relación con la existencia de una identidad latinoamericana. Sobre esta temática, Rodolfo Stavenhagen en su trabajo "La diversidad cultural en el desarrollo de las Américas: Los pueblos indígenas y los estados nacionales en Hispanoamérica” (s. f.) analiza lo siguiente:

El sincretismo cultural representado por el mestizaje se manifiesta en todos los niveles del quehacer humano y social. Si los europeos aportaron la lengua y religión oficiales, las leyes, las armas y las instituciones políticas, los indígenas aportaron la tecnología agrícola, los hábitos alimenticios, las creencias populares, las artesanías; y los africanos su música y su religión popular. Sería ocioso confeccionar listas de elementos culturales aislados y atribuirlos a tal o cual origen, aunque para la historia cultural de un pueblo esto no carece de importancia. Lo importante es reconocer que si bien una cultura, la europea, se impuso a la indígena, y si bien los contingentes de población africana sufrieron un proceso de desculturización por la naturaleza misma de su migración involuntaria, el resultado de estos procesos ha sido la emergencia en América Latina de una nueva cultura sincrética que se alimenta de sus raíces europeas, indígenas y africanas pero que ha desarrollado elementos propios que la distinguen (p. 16).

Conforme con lo expuesto, el mestizaje corresponde a uno de los procesos que caracteriza a Latinoamérica en general. En este sentido el sincretismo cultural ha sido una de las cualidades que en la actualidad y desde la conformación de los estados latinoamericanos se ha venido gestando, gracias a la convivencia y encuentro de diversas culturas como la europea, indígena, africana y otras más. Por tales motivos, no es casualidad que la mezcla cultural en los pueblos latinoamericanos se encuentre presente en la comida, la música e incluso en algunos edificios que datan de la época colonial.

El ideal en torno a la existencia de una identidad latinoamericana ha venido cambiando a través del tiempo y adaptándose a cada uno de los procesos histórico-culturales tanto de Latinoamérica como del mundo en general. Sobre esta situación, el teórico Fernando Aínsa en su artículo "Discurso identitario y discurso literario en América Latina" (2010) agrega:

En las últimas décadas se ha acumulado tanta retórica y lugares comunes sobre la identidad, sobre su importancia, los rasgos que definen su tipología -étnicos, objetos patrimoniales, historia, rituales, símbolos y costumbres- y sobre la idea de "ser nacional" en la que se reconocen los habitantes de un territorio, que la crisis actual del concepto en el marco de la sociedad globalizada en la que estamos inmersos, no nos sorprende (p. 13).

En última instancia, lo anterior indica que en la actualidad hablar sobre identidad, y más aún sobre una identidad latinoamericana, nos abre paso a la reflexión de que tales conceptos corresponden a procesos realmente complejos, lo cual nos conduce a un análisis retrospectivo sobre todos los procesos históricos (masacres, dictaduras, guerras, revoluciones y demás), culturales, sociales, económicos y conflictivos que han experimentado los pueblos latinoamericanos desde su conformación hasta la actualidad. Procesos que han calado hondo en el sentir de sus habitantes, quienes, en lugar de diferenciarse, luchan más bien por conformar una unidad.

Luego de efectuar un repaso de los antecedentes y fundamentos teóricos, es posible determinar que esta propuesta investigativa, orientada al análisis de la geografía literaria y el constructo identitario en El viaje 
sedentario (1994), resulta novedosa e indispensable, ya que, de momento, existen pocos estudios enfocados en la obra narrativa de Gonzalo Celorio.

\section{Movimientos realizados por El protagonista (NARRAdor)}

El viaje sedentario (1994) es un texto donde se mezclan tanto aspectos de la novela (presencia de un personaje principal llamado Gonzalo, el cual funge como entidad narradora y remite a hechos vividos en la niñez y su presente; además, nos ubica en un espacio: la Ciudad de México) como elementos críticos que coinciden con el género ensayo; quizás, incluso esa forma híbrida en la que se estructura la novela coincide en cierta parte con la diversidad o mezcla cultural representada, a su vez, por los pueblos latinoamericanos, entre ellos el México al que remite el personaje principal de forma tan entrañable.

En este apartado se tratará de explicar los movimientos que realiza el protagonista, a través del texto El viaje sedentario (1994); para ello, resulta interesante retomar el estudio de Ottmar Ette (2008), ya que en este el crítico realiza una explicación sobre los diversos y posibles recorridos realizados por los personajes dentro del texto literario. Así, Ette (2008) indica que:

Otra figura espacial básica del movimiento de viaje es la del vaivén entre dos o más lugares. El punto central de este modelo no es ni el viaje en sí, ni la partida o la llegada, sino la existencia casi simultánea de lugares separados en el espacio y en el tiempo (p. 57).

En el caso de la novela en estudio, podría afirmarse que el vaivén corresponde en tal sentido con el movimiento más relevante del personaje principal (Gonzalo), pues este se trasladará del presente al pasado a través de la memoria y los recuerdos, lo cual involucra un viaje de ida y regreso; es decir, la recurrencia entre el pasado y el presente será reiterada, y para ello se emplea como único medio de transporte la memoria histórica del protagonista. Lo anterior se complementa con lo expuesto por el teórico al mencionar que “[...] el viajero se mueve también dentro de la cronología propia de su viaje, que sin lugar a dudas crea su propia temporalidad. Más allá de ello, aquel también oscila entre varios tiempos históricos y culturales en su viaje temporal" (Ette, 2008, p. 29).

La obra se compone de dos divisiones (el viaje de ida y el de regreso), una titulada "De ida", cuyos apartados se centran en describir episodios de la niñez de Gonzalo, en relación con algunos espacios recurrentes y cotidianos como el barrio y la ciudad donde actualmente reside (Mixcoac). Al respecto de esta familiaridad de los espacios, De Certeau (2007) afirma: "Todo relato es un relato de viaje, una práctica del espacio. Por esta razón, tiene importancia para las prácticas cotidianas; forma parte de éstas" (p. 128). El viaje de ida inicia desde el escritorio, un espacio familiar en el cual escribe el protagonista y que lo liga a su padre, su origen. Ante este panorama, también resultan imprescindibles lugares como la casa, el jardín o el mercado, que en el siguiente apartado se abordarán con mayor amplitud.

Poco a poco se van describiendo los espacios que remiten al mundo interno de Gonzalo, hasta llegar a la mención de lo exterior que involucra ya no solo la casa en que tantos años ha habitado, sino lo mágico que ante los ojos del narrador resulta la infraestructura arquitectónica de la Ciudad de México en general. Destaca, de forma particular, el encanto que le produce la Catedral al mantener intactos arte y estructura que datan de la época colonial.

Otro aspecto fundamental en "De ida" es el viaje reflexivo experimentado por el narrador en relación con la música latinoamericana, en especial la música tropical de México y Cuba, para lo cual se valdrá de descripciones exóticas y pintorescas de los espacios donde se desarrolla, los salones de baile, cantantes y bailarines que vinieron a marcar un género (salsa, bolero) y una época en estos países y Latinoamérica en general. Sobre este apartado de El viaje sedentario (2014), el narrador manifiesta:

Antes, la música tropical estaba más o menos limitada a los cabarets, a las películas de rumberas, a las fiestas de vecindario, a los radios de los taxistas, a las rocolas de las marisquerías, aunque a veces rebasaba graciosamente sus fronteras, y en buena medida 
[...] empezó a escucharse como reivindicación de nuestra tan llevada y traída identidad [...], y dejó de llamarse "tropical" para

llamarse "afroantillana" (Celorio, 2014, pp. 89-90).

Cabe destacar que esta música se origina como resultado de la convivencia y mezcla de culturas, por ejemplo, tal es el caso de la música tropical que surge con fuerza en las islas de las Antillas e incluye muchos elementos de la cultura afrodescendiente (instrumentos, ritmo).

La segunda división del texto lleva como título "De regreso" y se conforma por apartados que ahondan aún más en el carácter crítico y reflexivo de la obra (al estilo de un ensayo). Se enfoca en establecer las condiciones actuales de monumentos, que por un tiempo desempeñaron una función importante para México y que fungen como evidencia de esa mezcla entre lo europeo y lo indígena. Así lo señala Amaryll Chanady (1996), cuando afirma que:

[...] en un ensayo titulado Crítica de la pirámide, el poeta y ensayista mexicano Octavio Paz subraya las diferencias internas profundas que marcan su país [...] Define al otro como la herencia generalmente inconsciente de los aztecas, que ha marcado casi toda la sociedad mexicana (p. 90).

Es decir, la esencia del elemento y la cultura indígena se comprenden como parte del ser mexicano.

\section{Manifestaciones esPaCiOTEMPORALES Y La CONSTRUCción DE UNA IDENTIDAD}

Al inicio del relato, el autor, a través de una nota previa, se dirige al lector y le explica que "este libro trata del espacio [...] Empieza por el espacio, mi escritorio, sobre el cual creo -recreo más bien- otros espacios [...] El viaje sedentario (1994) trata del espacio, pero también trata del tiempo que algunos espacios guardan para sí" (Celorio, 2014, pp. 9-10). De esta manera, el viaje del cual habla el personaje de Gonzalo (joven escritor), en primera instancia nos traslada desde su escritorio al pasado, para detenerse en los tiempos de la niñez, es aquí donde remite a la figura paterna como una de sus fuentes de inspiración y que recuerda con tanta nostalgia: "Papá transcurría los días y los insomnios sentado en su escritorio, inventando artilugios que nunca triunfarían [...] Yo sólo quería creer, a fuerza de nostalgia -aunque fuera prematura-, que papá estaba muerto en el cuarto de al lado" (Celorio, 2014, pp. 15-16). De acuerdo con lo expuesto, fue precisamente la figura del padre, en ese espacio representado por el escritorio, lo que inspira en el hijo ese arte de "crear" a través de una actividad tan extraordinaria como lo es la escritura. A esa actividad de crear, se refiere en páginas posteriores:

Es mi escritorio el paisaje que más miro. Cobija mis ensoñaciones y es, en sí mismo, mi ensoñación más recurrente [...] Cómo no escribir sobre mi escritorio, que me distrae de lo que sostiene y, celoso, me concentra en sus propios temas: en sus vetas arcanas, en sus pequeños cajones, en los múltiples compartimentos donde se ordena mi universo diminuto (Celorio, 2014, p. 19).

El espacio del escritorio, en este sentido, viene a representar no solo el pasado, que le trae al protagonista el recuerdo del padre, sino que evoca en él ese amor por la escritura misma, la cual se concibe, al final de cuentas, como su motivo de vida. Sobre este carácter emotivo del cronotopo en el ámbito familiar y biográfico del ser humano, Mijaíl Bajtín en Problemas literarios y estéticos (1986) explica que todas las determinaciones espacial-temporales, tanto en el arte como en la literatura, son inseparables unas de otras y siempre permanecen matizadas de forma emotiva y valorativa. Es decir, el arte y la literatura se encuentran impregnados de valores cronotópicos; así, cada motivo y momento destacable de la obra artística viene a constituir ese valor emotivo (Bajtín, 1986, p. 452).

El texto muestra, poco a poco, el universo personal de Gonzalo y sus espacios más íntimos, para luego trasladarnos hacia otros referentes espacio-temporales; de esta manera empieza a describir la casa donde habita en el presente:

Construida a finales del siglo XIX, la mía es una de las pocas casas de ladrillo y tapete -otrora característica del barrio de Mixcoac- sobreviviente de la voracidad comercial y de la explosión demográfica que convierten las casas antiguas 
en establecimientos mercantiles [...]. Mi casa es un tren, con sus vagones, su andén, sus estaciones, donde emprendo cotidianamente mi viaje sedentario (Celorio, 2014, pp. 22-27).

De acuerdo con La poética del espacio, de Gastón Bachelard (2000, p. 28), "[...] la casa es nuestro rincón del mundo [...] es realmente un cosmos". Lo anterior quiere decir que la casa, como elemento simbólico, no solamente se refiere a ese espacio de resguardo que brinda cobijo, refugio o seguridad. Para el personaje representa su propio universo, el lugar desde el cual emprende el viaje de escribir, producir, crear y desde el cual se define a sí mismo. Siempre en relación con el significado simbólico de este espacio, Bachelard afirma que la casa se define como uno de los mayores poderes de integración para los pensamientos, los recuerdos y los sueños del ser humano. En esa integración, el principio unificador es el ensueño. Así, el pasado, el presente y el porvenir proporcionan a la casa diferentes dinamismos, sin ella el individuo sería un ser disperso (Bachelard, 2000, pp. 29-30).

A través del uso de una metáfora, el narrador establece una comparación entre la casa que habita con un tren, lo cual permite brindarle a dicho espacio cierta movilidad o carácter dinámico. La actividad literaria que se produce desde la casa misma viene a ser un espacio para el arte, aquí se concentra el significado del oxímoron que encierra su "viaje sedentario", el que realiza desde su escritorio mediante el arte de la escritura.

El autor, a partir de las descripciones de algunos aposentos de la casa, tratará de destacar cómo se encuentran entrelazados o mezclados elementos tradicionales de la cultura, raíces y pasado mexicano, en contraste con otros artefactos modernos del presente:

Aun así, mi cocina conserva la estufa de carbón que estaba en la cocina original, de manera que a veces la casa entera huele a pueblo y recobran su imperio sobre los múltiples y especializados aparatos electrodomésticos el metate y el molcajete. El carbón huele a fiesta, a cazuela de barro, a mezcal [...] (Celorio, 2014, p. 31).

Se evidencia la intención del narrador al mencionar elementos de origen precolombinos que resaltan frente a otros representativos de la modernidad, quiere decir que, a pesar del tiempo transcurrido, esas raíces indígenas siguen presentes en el ser mexicano; en este sentido "el espacio conserva el tiempo comprimido" (Bachelard, 2000, p. 31). También, recurre a las sinestesias con el fin de evocar olores y sabores que recuerdan la cocina tradicional de los ancestros.

De este espacio lleno de magia, olores y sabores, la entidad narrativa nos mueve hacia otros sitios representativos, se produce un movimiento que va de lo interno (casa, recuerdos, mundo interior del protagonista) a lo externo, cada vez más en busca de los lugares que se ubican a las afueras de la casa, se trata del jardín y el mercado:

Ciertamente, la casa tiene un raro jardín en el que las estaciones se marcan con puntualidad de calendario y entran cuando los libros de texto dicen que deben entrar [...] acaso porque la glicinia, que allí crece desde hace un siglo, proceda del Mediterráneo [...] (Celorio, 2014, p. 24).

Con base en lo descrito, el jardín funciona como uno de los sitios mediante los cuales se puede observar el paso del tiempo, su fugacidad, cuando se cambia de una estación a otra. Tales referencias ponen en evidencia que "el cronotopo como la principal materialización del tiempo en el espacio constituye el centro de la concreción y plasmación representativa para toda la novela” (Bajtín, 1986, p. 460).

La concepción acerca del tópico de la diversidad que caracteriza los pueblos latinoamericanos se logra visualizar con recurrencia en fragmentos de El viaje sedentario (1994), como en este caso, donde el protagonista reflexiona sobre uno de los mercados más importantes de México en tiempos de la Conquista:

Entre las muchas cosas del Nuevo Mundo que sorprendieron a los conquistadores, brilla el mercado de Tlatelolco. Bernal Díaz del Castillo, al llegar a la Ciudad de México Tenochtitlan, se asombra ante la diversidad, la riqueza, la novedad de sus productos [...] los objetos preciosos de oro y plata, la ropa de algodón y de hilo, el cacao [...] (Celorio, 2014, p. 32).

No es casualidad que la diversidad de productos expuesta en uno de los mercados más impresionantes de la América precolombina nos lleve a pensar en cuán diversa vendría a ser toda Latinoamérica, con costumbres 
y tradiciones particulares, mercados, contextos, historias. Podría incluso parecer contradictorio, pero tales diferencias son las que tienden a identificar y unificar a los pueblos de la región. Luego de la referencia al mercado de los tiempos de la Colonia, el narrador retoma el presente y nos habla un poco sobre el mercado que se encuentra más cerca de su casa:

Mi cocina está provista de una gigantesca despensa: el mercado de Mixcoac, aledaño a mi casa [...] El mercado de Mixcoac es colorido [...] los mangos pelados, flores protuberantes; las papayas partidas en zigzag, coronas amarillas de rey mago. Las piñas con sus penachos mayas, los chicozapotes que trasminan sus mieles [...] Las celebraciones del mercado llegan hasta mi casa y se meten por puertas y ventanas. En Navidad oigo los villancicos [...] Y cada septiembre izo una bandera mexicana en la puerta de la casa [...] Y cada noviembre vuelvo a velar a mis muertos [...] (Celorio, 2014, pp. 31-39).

De lo anterior se destaca el colorido y diversidad del mercado, también se muestra como un lugar en el que transcurre el tiempo mediante las festividades durante épocas significativas del año, se trata en este sentido de un tiempo cíclico, que va y viene constantemente.

Tal como lo plantea Wolfgang Cziesla (1996): "Si se trata de grandes ciudades hay una relación muy estrecha con la urbanística, que por su parte trabaja en forma interdisciplinaria e integra disciplinas como arquitectura, desarrollo, historia, geografía o sociología de la ciudad” (p. 222). En este trabajo el tema de la ciudad es recurrente, se puede observar a través del texto cómo Gonzalo, el protagonista, poco a poco va mostrando las afueras de su hogar; así, luego del mercado se visualiza de forma panorámica parte de la ciudad en la que vive y se desenvuelve:

[...] la campana de la basura, las campanillas de las paletas heladas, el bufido climático de plátanos y camotes, el silbatido guajolotoso del policía de tránsito o el desahuciado del cartero o el chillante del globero, el grito mandibular de los que aún pregonan el gas, la miel de colmena, los asesinatos y pesquisas y violaciones [...] que ocurrieron anoche en mi colonia, acaso en mi calle, acaso en mi casa (Celorio, 2014, p. 50).

En el fragmento anterior se realiza un intento por contextualizar el ambiente actual de la Ciudad de México: un tanto desordenado, ruidoso, caótico; con diversidad de oficios y espacios que se tornan problemáticos, pues surgen como consecuencia del proceso de modernización por el cual han pasado la mayoría de centros urbanos en el mundo. La incertidumbre invade el interior del protagonista quien se cuestiona sobre los posibles hechos violentos que han de ocurrir en su propio entorno.

En páginas posteriores, la entidad narradora regresa al espacio personal representado por la casa, con el fin de despedirse, pues luego de diecisiete años de vivir en ella debe desalojarla a petición de las inquilinas. Ante el sentimiento de tristeza que le provoca la repentina situación, Gonzalo expresa: "Tengo la premonición dolorosa que, en yéndome yo, la casa habrá de ser demolida como demolieron hace algún tiempo la casa de enfrente, que fungía como escuela secundaria" (Celorio, 2014, p. 58). No es de extrañar los sentimientos encontrados, pues la casa, aparte de brindarle abrigo y resguardo por tantos años, se convirtió en su espacio de vida, en el sitio que ha sido testigo de la labor más importante para el protagonista, la escritura; aquí "los valores de intimidad se dispersan en ella" (Bachelard, 2000, p. 35).

Ante esta situación, el personaje menciona:

Empecé a escribir sobre la casa y su arquitectura ferroviaria, sobre su glicinia, sobre el barrio de Mixcoac y sus vecinos subsidiarios [...] y ya no pude irme porque las cosas y la gente, una vez nombradas y descritas, cobraron dignidad y estatura y se hicieron entrañables (Celorio, 2014, p. 66).

Luego de los momentos nostálgicos vividos en relación con el desalojo de la casa, el autor dedica un apartado para hablar de las experiencias vividas en lugares de esparcimiento, como algunos bares de música tropical en la Ciudad de México. Sobre este apartado, resulta interesante la mención que realiza de un lugar en especial en el cual compartió buenos momentos con amigos y músicos, entre ellos: El Combo, Pedro Arévalo y su grupo Los Mulatos, se trata del Bar León.

El narrador se ubica en otros espacios de la ciudad, justo cerca de la magnífica e impresionante Catedral de México: 
Atrás de Catedral quedó el viejo Bar León con sus meseros de siempre [...] pero sin su público primigenio, desplazado por profesores y estudiantes universitarios, jerarcas de inciertas burocracias y mercaderes de la difusión, que un día se posesionaron del bar en busca de "lo auténticamente nuestro" [...] Al bolero seguía la rumba buena, y cuando El Combo sentía el entusiasmo del público tocaba, en el momento más portentoso de su actuación, una pieza en la que se iba privilegiando, alternadamente, a cada uno de los instrumentos [...] (Celorio, 2014, pp. 73-74).

El Bar León fue un lugar muy frecuentado por Gonzalo, en ese ambiente festivo y alegre intentaba olvidarse, por un lapso, de los problemas o conflictos personales. El paso del tiempo a través de muchos sitios de la ciudad, en este caso del Bar León, fue generando cambios e incluso acabando con esos establecimientos que con tanta nostalgia recuerda el protagonista, sitios con los que se identificó en determinado tiempo una generación (década de los setenta).

Luego de estas anécdotas y reflexiones sobre una parte de la música latinoamericana, el autor dedicará todo un apartado para hablar sobre la Catedral de México. Se trata de un ensayo escrito por Gonzalo Celorio ("Tiempo cautivo: la Catedral de México") y debido a la importancia que para él representa, decide introducirlo dentro de El viaje sedentario (1994). A partir de estas descripciones, las referencias a la vida personal del protagonista se omiten casi por completo para dar paso a una prosa cada vez más crítica, todo en relación con diversas edificaciones (monumentos, iglesias, estatuas, edificios) que han sido heredadas a la ciudad desde los tiempos previos y durante la Conquista. Sobre la Catedral y lo que esta significa para los mexicanos, el autor expone:

De su transcurso por espacios profanos, el tiempo no deja otra huella que la destrucción. Los espacios sagrados en cambio, conservan viva la memoria de los siglos [...] los espacios sagrados no pierden el tiempo: lo retienen, cautivo, en sus recintos [...] todo espacio sagrado es almacén del tiempo, a un tiempo presente y sucesivo [...] espacio sagrado, la Catedral es el perímetro del tiempo detenido [...] (Celorio, 2014, p. 101).

Tiempo y espacio se funden ahora en la Catedral; de acuerdo con Celorio, aquí el tiempo en lugar de destruir, se mantiene atrapado, cautivo, como un testigo fiel de los hechos históricos que han transcurrido alrededor de ella durante siglos. Más adelante, siempre en relación con el tema de la arquitectura colonial de México, el autor destaca la constante e innegable presencia de lo indígena en cada una de las edificaciones. $\mathrm{Al}$ respecto señala:

Herederos de espléndida y singular tradición arquitectónica, los indios subordinaron sus impulsos plásticos a cánones impuestos. No obstante, supieron firmar las obras que con sus manos fabricaron: signos, colores, ornamentos indígenas, que se entremeten, sutiles, quizás involuntariamente, en las construcciones cristianas (Celorio, 2014, pp. 114-115).

Esto viene a suceder no solo en México, sino en toda Latinoamérica; una mezcla de estilos, arquitectura, culturas y de percepciones.

En el apartado "De regreso", el yo discursivo introduce diversos aspectos históricos que involucran movimientos artísticos y arquitectónicos implantados en México durante la época Virreinal. Se realiza todo un esbozo de edificaciones e incluso de artistas mexicanos que se han preocupado por conservar y reivindicar parte de esa infraestructura que de cierta manera constata o reafirma su identidad. De esta manera, el yo discursivo, con respecto a estos movimientos y siempre en relación con el tema de la Catedral, expone que:

Por el aluvión de estilos que se superponen en la Catedral; por la simbiosis y la mixtura de las diferentes culturas que en ella convergen; por el origen exótico de muchas de sus riquezas; por la fe de un pueblo en ella depositada -en sus santos y en sus vírgenes y en sus ángeles y en sus reliquias; por las mitologías que ahí se concentran y por las que de ahí proceden, la historia de su construcción [...] podrían pertenecer a lo que Alejo Carpentier llamó “lo real- maravilloso" (Celorio, 2014, p. 132).

Ante la presencia de esa mezcla exótica, de culturas y obras artísticas, surge por ejemplo el barroco latinoamericano que involucra tanto lo europeo como lo indígena. Y es la complejidad también de nuestros hechos históricos lo que nos hace incluso incomprensibles ante la perspectiva europea, por ejemplo. Así lo plantea el autor cuando se refiere a uno de los monumentos históricos de la Ciudad de México: "Como tantas manifestaciones artísticas de nuestra ciudad, la estatua ecuestre de Carlos IV no escapa a la paradoja y la 
sinrazón” (Celorio, 2014, p. 135). Se podría inferir que para el autor este monumento vendría a representar un vestigio o referente de la monarquía europea que, ya para los tiempos actuales en el continente americano, su sentido y simbolismo no tiene mayor valor.

También se amplía el discurso en relación con el carácter mítico o fantástico de la arquitectura latinoamericana:

Si en lo inexplicable reside lo fantástico, no puedo, sin conjurarla, explicar esta condición de la arquitectura prehispánica. Así las cosas, me limito, en éste y en los casos sucesivos de la arquitectura virreinal, decimonónica y contemporánea, a inventariar [...] algunas imágenes que me parecen fantásticas precisamente por insólitas y por inexplicables (Celorio, 2014, p. 159).

Lo anterior engloba no solo cada una de las etapas históricas más significativas de Latinoamérica, sino que también involucra la presencia de la infraestructura mística que aún se conserva en el presente. Por último, la obra nos conduce a un final abierto donde se invita a que los mismos latinoamericanos hagan un análisis introspectivo y retrospectivo sobre los acontecimientos históricos que dieron origen a estos pueblos y, de esa manera, reflexionar sobre aquellos aspectos que han venido a formar parte de ese sentir, comúnmente llamado identidad.

El texto culmina con una mención a aquellos edificios que, a pesar del tiempo y tantos otros factores, aún sobreviven en medio de la gran Ciudad de México:

Sobrevive también la arquería del portal de peregrinos que después del terremoto del 85 que los mexicanos, maestros del eufemismo, llamamos "temblor", quedó en pie, milagrosamente como una hoja de papel suspendida en el aire en medio del derrumbe [...] Enfrente, el edificio Guardiola con sus modernidades art-déco y el churrigueresco Palacio de los Azulejos [...] (Celorio, 2014, pp. 167-168).

En este sentido, la novela en estudio puede concebirse como un preámbulo a un debate casi interminable, en relación con el proceso que involucra el renacer de una identidad latinoamericana a través de los últimos siglos. De acuerdo con este planteamiento, Rodolfo Stavenhagen (s. f.) afirma:

La búsqueda de la identidad permea las obras culturales latinoamericanas en el siglo veinte, particularmente la literatura y otras ramas de la expresión artística. Los analistas y críticos de la novela y del ensayo, de las formas musicales, de la expresión pictórica y escultórica, subrayan una y otra vez este hilo conductor de la cultura latinoamericana contemporánea: la búsqueda de la identidad. Esta tarea se da tanto en el nivel propiamente nacional, como en el regional y continental. Por una parte, se explora la "esencia" de lo mexicano, lo peruano [...]; por la otra, se reafirma la unidad de América Latina más allá de las fronteras nacionales, y se proclama que el verdadero nacionalismo no está limitado por las fronteras políticas, sino que es también un nacionalismo regional latinoamericano (párr. 44).

El viaje sedentario (1994), de Gonzalo Celorio, se encuentra impregnado de tiempo y espacios emotivos que, desde la perspectiva del narrador, forman parte de su ser, lo constituyen, lo definen como un individuo en transformación, no estático. Tal y como lo afirma Bajtín "En la literatura el tiempo constituye el principio rector del cronotopo. Este como categoría formal y de contenido, determina (en gran medida) también la imagen del hombre en la literatura" (1986, p. 270). En este sentido, la literatura, como una actividad y producto de la cultura, también, representa uno de los medios por los cuales el ser humano puede contribuir a la construcción de una identidad.

\section{Conclusiones}

Con este trabajo queda en evidencia que los espacios descritos por el personaje principal a lo largo del texto se encuentran relacionados con esa intención de identificarse, de referirse a lo propio, en un país tan diverso y rico a nivel cultural como México. El propósito de tal caracterización de los espacios en la obra lleva al lector a identificarlos como parte de la esencia y los elementos que en su totalidad conforman la identidad del pueblo mexicano. La región latinoamericana se define como una zona multicultural, un espacio geográfico donde convergen poblaciones de distintos orígenes, con creencias, mitos, costumbres y credos 
religiosos igualmente diversos. Parte de esta diversidad se constata en la novela en el apartado que habla sobre las primeras manifestaciones de la música tropical en Ciudad de México. También por las evidencias arquitectónicas y de los espacios estructurales que, como menciona Gonzalo Celorio en El viaje sedentario (1994), aún se conservan en las ciudades más importantes durante la Conquista y Colonización, tal es el caso de México y Perú. Todo lo anterior da fe de la complejidad y la mezcla que guarda la Ciudad de México, situación que también podría presentarse en otras ciudades o países latinoamericanos.

De acuerdo con las descripciones realizadas en el texto sobre los vestigios arquitectónicos, edificios y monumentos que se conservan en la Ciudad de México, las personas que comparten este espacio geográfico han creado un sentimiento nacionalista que los hace identificarse y diferenciarse. Ese sentimiento nacionalista retroalimenta la idea de lo que implica ser mexicano, es decir, esos objetos poseen un significado entrañable y dan voz a lo que ocurrió en el pasado. Son la prueba genuina del devenir histórico que también forma parte del origen y el proceso de construcción de la identidad de un pueblo.

El discurso de Celorio en El viaje sedentario (1994) se vale de descripciones que realizan un llamado a la memoria histórica, los lugares del pasado se proyectan con nostalgia, emotividad y añoranza; ya que desde la perspectiva del narrador fue esplendoroso y pujante en contraste con el presente caótico donde impera la soledad y el protagonista se muestra como un sujeto en crisis. En última instancia, México en su totalidad se visualiza como el cronotopo del encuentro donde "predomina el matiz temporal y se distingue por el alto grado de intensidad emocional valorativa" (Bajtín, 1986, p. 452). Aquí convergen presente y pasado y en él se acumulan capas de sentido e históricas, desde la época colonial hasta la actual.

\section{BibLIOgRAFÍA}

Aínsa, F. (1986). Identidad cultural de Iberoamérica en su narrativa. Madrid: Gredos.

Aínsa, F. (2010). Discurso identitario y discurso literario en América Latina. Amérika,1. doi: 10.4000/amerika.478

Bachelard, G. (2000). La poética del espacio. (E. de Champourcin, trad.). México: Fondo de Cultura Económica.

Bajtín, M. (1986). Problemas literarios y estéticos. La Habana: Editorial Arte y Literatura.

Beltrán, R. (2006). Tres lindas cubanas de Gonzalo Celorio. Revista de la Universidad de México, 29, 96-99.

Beltrán, R. (2014). Los raros: El metal y la escoria, de Gonzalo Celorio. Revista de la Universidad de México, 129, 92-93.

Celorio, G. (2014). El viaje sedentario. México: Tusquets.

Chanady, A. (1996). Nuestra América mestiza y la conceptualización de la especificidad latinoamericana. En F. Theodosíadis (Ed.), Alteridad ¿La (des)construcción del otro? Yo como objeto del sujeto que veo como objeto (pp. 83-104). Bogotá: Cooperativa Editorial Magisterio.

Cziesla, W. (1996). Metrópolis latinoamericanas como escenarios en la literatura. En M. Rall y D. Rall (Eds.), Letras comunicantes. Estudios de literatura comparada (pp. 219-248). México: Universidad Autónoma de México.

De Certeau, M. (2007). La invención de lo cotidiano. Relatos de espacio. México: Universidad Iberoamericana.

Ette, O. (2008). Literatura en movimiento: espacio y dinámica de una escritura transgresora de fronteras en Europa $y$ América. Madrid: Consejo Superior de Investigaciones Científicas.

Krieger, P. (1998). México, ciudad de papel, de Gonzalo Celorio. Revista Reseñas Anales del Instituto de Investigaciones Estéticas, 20(72), 165-167.

Stavenhagen, R. (s. f.). La diversidad cultural en el desarrollo de las Américas: Los pueblos indígenas y los estados nacionales en Hispanoamérica. [doc]. Recuperado de http://www.oas.org/udse/documentos/stavenhagen.doc 